\title{
Anaesthetic management of a parturient with severe kyphoscoliosis
}

\author{
Bansal N ${ }^{1}$, Gupta $S^{2}$
}

${ }^{1}$ Assistant Professor, Department of Anaesthesia ${ }^{2}$ Associate Professor, Department of Urology, Nepalgunj Medical College, Nepalgunj, Nepal

\begin{abstract}
Use of neuraxial block in a patient with severe kyphoscoliosis is controversial. We describe the anaesthetic management by spinal anaesthesia of a parturient with severe kyphoscoliosis in obstructed labour. The perioperative course was uneventful. We suggest that a patient with severe kyphoscoliosis may be successfully managed by spinal anaesthesia for caesarean section.
\end{abstract}

$\mathrm{K}$ yphoscoliosis is forward and lateral bending of the spine. It usually develops due to tuberculosis in developing countries ${ }^{1}$. It commonly affects the dorsal and lumbar spine. Only few cases of anaesthetic management of severe kyphoscoliotic patients with pregnancy are reported. Moreover, there are no uniform guidelines for obstetric anaesthesia in such patients ${ }^{2}$. We here report anaesthetic management of a patient with severe kyphoscoliosis who presented in obstructed labour due to cephalopelvic disproportion with fetal distress.

\section{Case report}

Twenty one year old primigravida, $53 \mathrm{Kg}$ in weight, $125 \mathrm{~cm}$ tall presented to us in labour at 37 weeks of pregnancy. She was diagnosed to have obstructed labour due to cephalopelvic disproportion with fetal distress. Hence, she was posted for emergency caesarean section. On assessment she was found to have severe kyphoscoliotic deformity of the spine. On history we found that she had suffered from tuberculosis of spine at the age of 6 years. It was complicated with the development of multiple abscesses in the back which had burst forming pus discharging sinuses. After that she took complete course of antitubercular drugs for one year but developed spinal deformity. She had poor effort tolerance in pre-pregnant stage. She developed breathlessness during pregnancy which progressed to grade III dyspnoea in the last trimester.

On examination she had tachypnoea with respiratory rate 36 breaths per minute. Her pulse rate was 100 beats/min and blood pressure was 110/70 $\mathrm{mmHg}$. The anteroposterior distance of the chest was increased because of the overcrowding of the ribs (Fig 1). On auscultation of the chest she had bilateral vesicular breathing with no added sounds. She had no neurological deficit. Other systemic examination revealed no significant finding. Examination of the back revealed multiple scars of healed sinuses (Fig 2) and the deformity of the spine. Her investigation revealed haemoglobin of $12 \mathrm{gm} \%$. Urine examination parameters were within normal limits. Because of the emergent situation no further investigations to assess pulmonary function could be done. Her arterial oxygen saturation was $94-96 \%$ on room air. In view of the compromised pulmonary reserve as judged clinically, it was decided to administer regional anaesthesia. Equipment and drugs for resuscitation in case of any emergency were kept ready. Alternative plan in case of failed spinal was local infiltration anaesthesia with local anaesthetics. General anaesthesia was not planned because of lack of facility for postoperative ventilation. She was positioned in right lateral decubitus position for administration of spinal anaesthesia. The landmarks were not clear and it was difficult to get the intervertibral space. Puncture was successful in $4^{\text {th }}$ attempt, in the space just below the hump. We administered $1.5 \mathrm{ml}$ of $0.5 \%$ Bupivacaine. A pillow was kept under the shoulders to prevent the ascent of the drug to higher levels. The sensory block was achieved up to T6 level after five minutes and blood pressure came down to $80 \mathrm{mmHg}$. She required injection Mephenteramine $3 \mathrm{mg}$ intravenously for the correction of hypotension once. After that surgery went off smoothly and she delivered a live healthy baby weighing $2.8 \mathrm{Kg}$.

\footnotetext{
Correspondence

Dr. Nirupma Bansal

Nepalgunj Medical College Teaching Hospital

Kohalpur, Banke

Nepal

E-mail: sandyneeru@yahoo.com
} 
Post operatively, the X-ray spine (Fig 3) and X-ray chest (Fig 4) were done. X ray chest showed the overcrowding of the ribs and reduced lung span. In lateral view of the thoracolumbar spine there was severe angular kyphosis. Angle of Kyphosis measured by method as described by Dickson was 105 degrees. But surprisingly there was no neurological deficit ${ }^{4}$. Cobb`s angle for scoliosis was

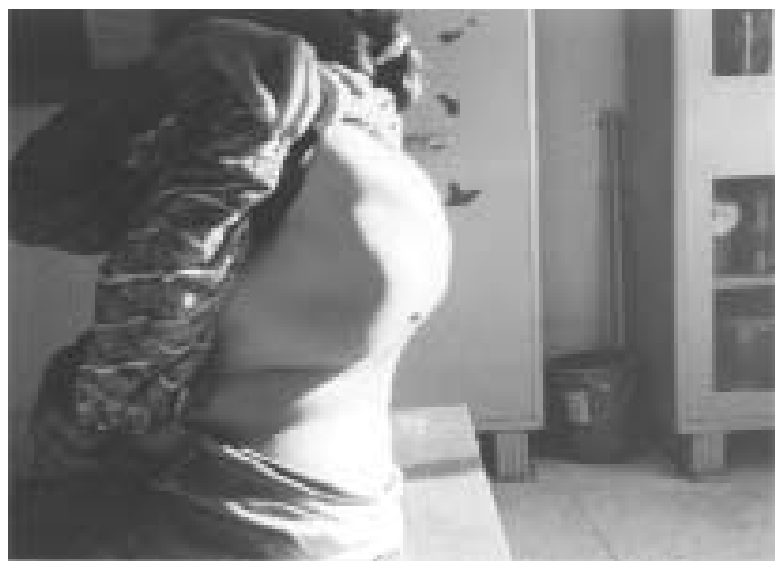

Fig1: Increased anteroposterior diameter of chest

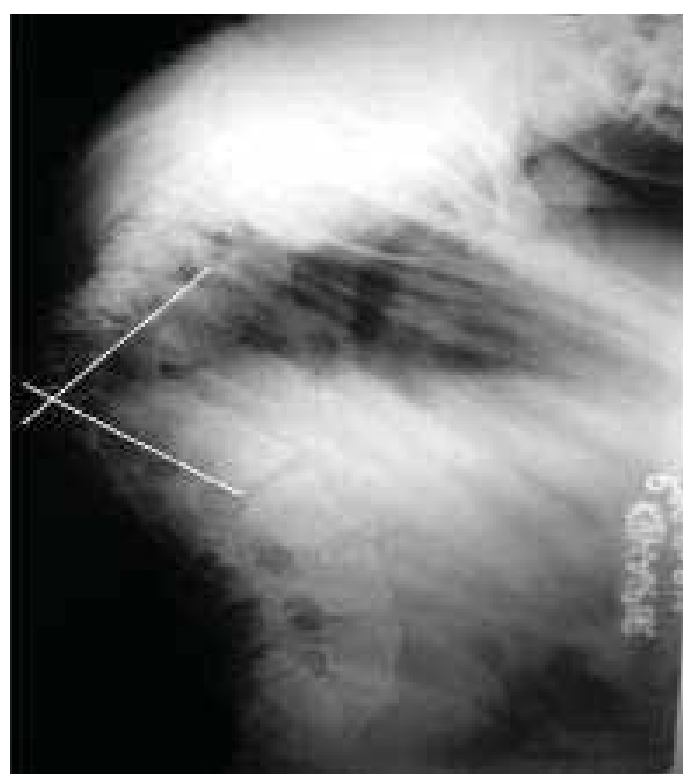

Fig 3: Lateral view of thoraco lumbar spine

\section{Discussion}

With the use of modern antitubercular treatment severe kyphoscoliosis due to tuberculosis is rare nowadays. Kyphoscoliosis produces a restrictive respiratory disorder. The severity of pulmonary impairment can be correlated with the angle of the deformity. Weinstein and colleagues reported that Cobb's angle above 60 degrees results in progressive pulmonary and cardiac failure ${ }^{6}$. Harrison et al reported that pulmonary impairments are most notable at kyphosis angles $>55$ degrees ${ }^{7}$. In the
30 degrees $^{5}$. Post-operatively pulmonary function test was done and the vital capacity was 1.5 litres. However the forced vital capacity and forced expiratory volume in 1 second could not be tested because of the lack of facilities. Her dyspnoea improved from grade III to grade II, 36 hours postoperatively.

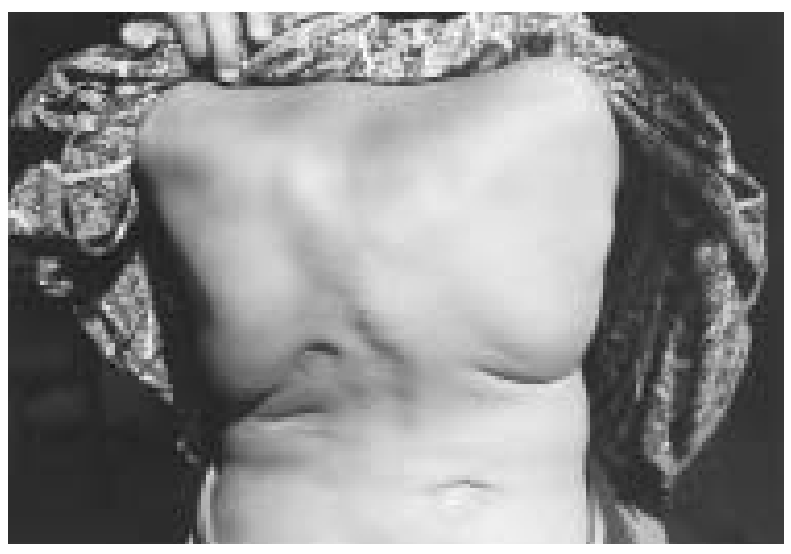

Fig 2: Back showing scar of healed sinuses

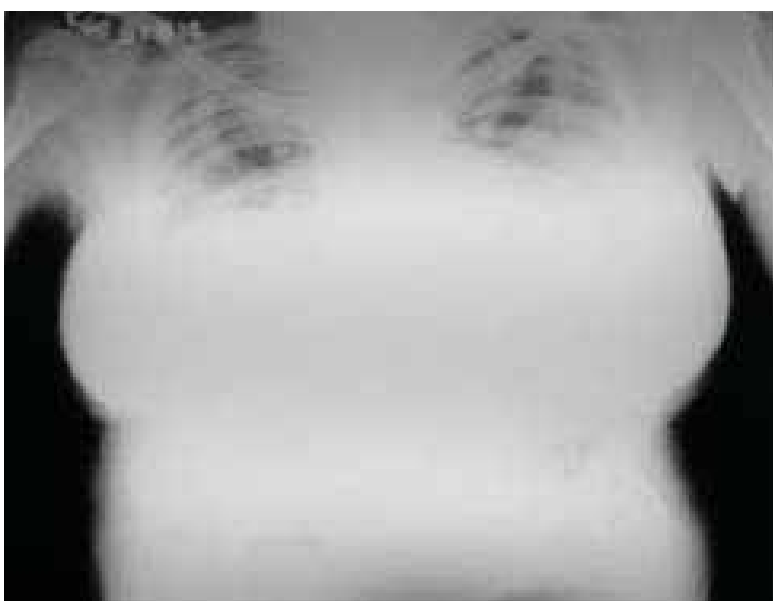

Fig 4: X-ray chest (PA view)

present case Cobb's angle was 30 degree and angle of kyphosis was 105 degrees. So there was high possibility of chronic hypoventilation, ventilation perfusion mismatch and increased pulmonary artery pressure in the pre-pregnant state.

During pregnancy minute ventilation volume increases by $40-50 \%$ due to increase in tidal volume with relatively unchanged respiratory rate in normal 
parturient. This is mainly achieved by alterations in the thoracoabdominal architecture ${ }^{8}$. These adaptations are not possible in kyphoscoliotic patients and diaphragm is entirely responsible for all increments in minute ventilation. But this is also constrained as the enlarging uterus enters the abdomen in the midgestation leading to decrease in functional residual capacity and closing capacity. Thus ineffective ventilation leads to ventilation perfusion mismatch, decreased arterial oxygen content, pulmonary vasoconstriction and increase in pulmonary artery pressure. Since tidal volume cannot increase, any increase in minute ventilation is achieved by increase in respiratory rate, thus increasing the work of breathing. These cardiopulmonary changes result in increased maternal morbidity as well as requirement for the assisted ventilation ${ }^{8}$. However, successful pregnancy without ventilator support has also been reported ${ }^{9}$.

Cardiac output increases during pregnancy more so during the last trimester. This increase further increases the pulmonary artery pressure leading to intolerable load on right ventricle and precipitating the right heart failure. Fixed pulmonary hypertension, unresponsive to oxygen therapy carries a grave prognosis and is an indication for termination of pregnancy. Death during peripartum period is common in parturient with pulmonary hypertension ${ }^{10}$.

General anaesthesia may be chosen in such patients because of patient's preference or maternal cardiopulmonary disease ${ }^{11}$ or because of technical difficulties related to regional block. But there can be hazardous increase in pulmonary artery pressure leading to right heart failure. Positive pressure ventilation decreases venous return and along with negative ionotropic effect of anaesthetic agents can lead to severe decrease in blood pressure. Coughing and bucking at the end of the surgery may transiently but significantly decreases functional residual capacity, resulting in further ventilation perfusion mismatch and hypoxemia ${ }^{12}$. Postoperatively after general anaesthesia elements of laryngeal incompetence and impaired swallowing further decreases the airway defence mechanisms. All these factors together can lead to delay in extubation and need for postoperative ventilation ${ }^{13}$. In the present case patient was tachypnoic with a respiratory rate of 36 breaths/min with involvement of the accessory muscles but she was maintaining arterial oxygen saturation of $94-96 \%$ on room air. Ventilator was not available in case the need arose. Hence spinal anaesthesia was planned.

During pregnancy due to the increased intraabdominal pressure and engorged veins in the epidural space the subarachnoid space is decreased. Hence, usual doses may lead to higher block ${ }^{14}$. Adjusting the doses according to height and weight gives desirable level of sensory and motor block with lesser incidence of hypotension ${ }^{15}$. But severe kyphoscoliosis can be associated with decreased volume of cerebrospinal fluid ${ }^{14}$ and even lower doses of local anaesthetics may achieve higher than expected level of block with more incidence of hypotension. This happened in our case also. Only $1.5 \mathrm{ml}$ of $0.5 \%$ Bupivacaine $(7.5 \mathrm{mg})$ was used which produced the sensory block level up to sixth thoracic vertebra and patient became hypotensive which was corrected with the use of vasopressor. Studies comparing the different doses of local anaesthetics in severe kyphoscoliotic patients are lacking. Although there are reports that in patients with severe curves hyperbaric solution may pool in the dependent portion of the spine and results in inadequate block $^{16}$. Supplementing the block with isobaric preparation of local anaesthetic may improve the quality of block.

Other problems are of unsuccessful insertions and multiple attempts before successful insertion ${ }^{17}$. We too could enter the subarachnoid space in the fourth attempt. For such technically difficult cases spinal needle insertion through lumbosacral space ${ }^{18}$ and sacral foramina ${ }^{19}$ have been reported with increased incidence of successful puncture.

Local infiltration anaesthesia is an alternative in case of difficult spinal or epidural block and where general anaesthesia cannot be given either because of patients compromised condition or because of lack of facilities. This has been successfully administered in parturients with the use of long spinal needles with $0.5 \%$ Lignocaine with Epinephrine ${ }^{20}$. Fetal outcome proposed via this technique is better when compared to general anaesthesia ${ }^{21}$.

There are few reports of anaesthetic management in kyphoscoliotic parturients using epidural, combined spinal epidural $^{22}$, continuous spinal anaesthesia ${ }^{16}$ and general anaethesia ${ }^{11}$ with successful outcomes. So depending on the facilities available for the peripartum period, any anaesthetic technique can be selected anticipating the difficulties.

\section{Conclusion}

To conclude, this report supports the feasibility of spinal anaesthesia in patients with severe kyphoscoliosis.

\section{References}

1. Tuli SM. Tuberculosis of the spine. New Delhi: Amerind Publishing Co;1975.

2. Kuczkowski KM. labour analgesia for patients with an uncommon disorder: a common dilemma in the delivery suite. Obstet Gyenocol Surv. 2003 Dec; 58 (12): 800 -3. 
3. Dickson, J.A.S Spinal tuberculoisis in Nigerian children: A review of ambulant treatment. J. Bone Joint surgery 1967; 49 : $682-94$.

4. Tuli SM. Treatment of neurological complications in tuberculosis of the spine. J Bone Joint surgery. 1969;51:680-92.

5. Cobb JR. Outline for the study of scoliosis. Instructional course lecture. Am Acad Orthop Surg. 1948; 5:261.

6. Weinstein SL, Zavala DC, Ponseti IV. Idiopathic scoliosis long term follow up and prognosis in untreated patients.J Bone Joint Am 1981;63:70212.

7. Harrison RA, Siminoski K, Vethanayagam D, et al. Osteoporosis-related kyphoscoliosis and impairement in pulmonary function: a systematic review. J Bone Miner RES. 2007;22(3) :44757.

8. Kahler CM, Hogl B, Hobeler R, et al. Management of respiratory deterioration in a pregnant patient with severe kyphoscoliosis by non invasive positive pressure ventilation. Wien Klin Wochenschr. 2002 Oct 31; 114 (19-20): 874-7

9. Yim R, Kirschner K, Murphy E, et al. Successful pregnancy in a patient with spinal muscular atrophy and severe kyphoscoliosis. Am J Phys Med Rehabil. 2003 Mar; 82(2): 222 - 5.

10. Gummerus M, Laasonen H. Eisenmenger complex and pregnancy.Ann Chir Gynaecol. 1981;70:339.

11. Gupta S, Singaria G. Kyphoscoliosis and pregnancy.IndianJAnaesthesia.2004;48(3):21520.

12. Bickler PE,Dueck R, Prutow RJ.Effects of barbiturate anaesthesia on functional residual capacity and ribcage/diaphragm contribution to ventilation. Anesthesiology 1987;66:147.
13. Baydur A, Milic Emili J. Respiratory mechanics in kyphoscoliosis. Monaldi Chest Dis. 1993; 48(1): 69-79.

14. Klienman W, Mikhail M-Spinal,Epidural, and Caudal Blocks.In :Morgan GE, Mikhail SM, Murray MJ,editors. Clinical Anaesthesiology. $4^{\text {th }}$ ed. New York:Mc Graw Hill Inc; 2006:289323.

15. Harten J.M. Effect of a height and weight adjusted dose of local anaesthetic for spinal anaesthesia for elective Caeserian section. Anaesthesia. 60(4):348-53.

16. Moran DH, Johnson MD. Continuous spinal anaesthesia with combined hyperbaric and isobaric bupivacaine in a patient with scoliosis. Anesth Analg. 1990; 70 :445.

17. Feldstein G, Ramanathan S. Obstetrical lumbar epidural in patients with previous posterior spinal fusion for kyphoscoliosis. Anesth Analg. 1985;64:83.

18. Taylor JA. Lumbosacral subarachnoid tap. J Urol. 1940;43:561.

19. Martinez C, Wulfsohn N. Sacral foraminal subarachnoid block: An expanded case report. Regional Anesthesia and Pain Medicine. 2003;23(3):311-4.

20. Cooper MG, Feeney EM, Joseph M, McGuinness JJ. Local anaesthetic infiltration for caesarean section. Anaesthesia and Intensive Care. 1989;17:198-201.

21. Ranney B,Stannage WF. Advantages of local anaesthesia for caesarean section. Obstet \& Gynecol. 1975;36:159-63.

22. Pan PH, Moore CH. Doxorubicin-induced Cardiomyopathy:Three Case Reports of Anesthetic Management for Caeserean and Vaginal Delivery in Two Kyphoscoliotic Patients. Anesthesiology. 2002;97:513-5. 